\title{
In vitro propagation of Althaea officinalis: the role of plant growth regulators in morphogenesis
}

\author{
A. Mujib *, Tanu Pipal, Muzamil Ali, Dipti Tonk, Nadia Zafar, Basit Gulzar \\ Department of Botany, Jamia Hamdard (Hamdard University), New Delhi, India
}

\begin{abstract}
Althaea officinalis L. (marshmallow) belonging to the Malvaceae family, is an important plant that contains a variety of important phytocompounds including asparagine, pectin, flavonoids, polyphenolic acid, and scopoletin. The yield of these compounds can be improved using biotechnological methods that allow for a steady and continuous regeneration of plant material. To the best of our knowledge, thus far, the in vitro clonal multiplication of marshmallow has not been attempted on a large scale. Therefore, in this study, we developed callus induction and multiple shoot regeneration protocols from explants. All the explants, i.e., roots, nodes, and leaves, evoked compact white or yellow calli in a medium supplemented with 2,4-dichlorophenoxyacetic acid (2,4-D), which grew vigorously. The callus induction frequency was the highest (62.1\%) from stem nodes, followed by leaves (39.1\%) and roots (27.5\%). The differential behavior of explants in response to various plant growth regulators (PGRs) was studied. The calli from leaves and roots were noted to be non-organogenic/embryogenic in media containing different PGR concentrations and have been described in this communication. The stem nodes used were cultured on MS media amended with different concentrations of benzyl-amino-purine (BAP: 0.5, 1.0, and 2.0 mg/l). Multiple shoots were formed at variable numbers, the maximum being in a medium supplemented with $1.0 \mathrm{mg} / \mathrm{l}$ of BAP. The induced shoots were rooted in IBA-, NAA-, and IAA-amended media, where IBA at $0.5 \mathrm{mg} / \mathrm{l}$ induced a maximum number of roots ( 8.8 roots/shoot). The regenerated plants were transferred to plastic pots, filled with soilrite and soil (1:1), and finally, transferred to outdoor conditions.
\end{abstract}

Key words: callus induction, 2,4-D, multiple shoot, BAP, IBA, NAA, rooting

\section{Introduction}

Althaea officinalis L., commonly known as marshmallow, is a plant indigenous to Africa. It is also found in most countries of Europe, from Denmark to southern Europe. It primarily grows in salt marshes, in damp meadows, by the sides of ditches, in sea, and on the banks of tidal rivers. The plant is grown as an ornamental and medicinal plant (Anonymous, 2003; Ali Esmail Al-Snafi, 2013). The flowers are mallow shaped and are in full bloom during the months of August and September. Many of the mallows are consumed as vegetable foods. Moreover, the leaves, flowers, and roots possess medicinal properties (Hage-Sleiman et al., 2011). A. officinalis is conventionally used against the irritation of mucous membranes, for treating throat and gastric ulcers, and for making mouthwashes. The flower extract can reduce hyper-lipidemia, gastric ulcers, and platelet aggregation (Blumenthal et al., 2000). The antioxidant activity of various parts of this plant has also been demonstrated in a number of other studies (Elmastas et al., 2004; Sadhighara et al., 2012). The confection made from its roots has been used for sore throat treatment since ancient times. In the Chinese alternate medicinal system, the plant is used as a stimulant for breast milk production; it also soothes bronchial tubes (Petkewich, 2006).

The milkweed plants are primarily propagated by seeds. This reproductive method has a number of limitations including unpredictable seed germination, long germination time, and poor seedling production with

\footnotetext{
* Corresponding author: Department of Botany, Jamia Hamdard (Hamdard University), New Delhi - 110062, India; e-mail: amujib3@yahoo.co.in
} 
high heterozygosity in the progeny (Anonymous, 2003). Micropropagation is currently used for the preservation and rapid large-scale multiplication of important germplasms (Dube, 2011). The preservation of elite stocks in minimal media or an in vitro slow growth is another important advantage of an in vitro propagation method (Uyoy, 2003). Because of its numerous benefits, micropropagation has been utilized in a number of plant groups as a good alternative and complementary propagation method. In Althaea, successful callus induction was achieved on an MS medium supplemented with $5-\mu \mathrm{M} 2,4-\mathrm{D}$, and later, adventitious shoot formation was noted on 2,4-D $(7.5 \mu \mathrm{M})+20 \mu \mathrm{M}$ adenosine sulfate-added liquid medium (Naz and Anis, 2012). Munir and coworkers (2012) optimized conditions for the fast induction of callus and the single use of 2,4-D. Further, BAP + NAA combinations were noted to be very productive for the induction of callus. The cultivation of calli in solid and liquid suspensions is often carried out in a variety of bioreactors to scale up the production of biomass and phytocompounds, as most of the plants including Althaea contain immensely valuable compounds such as asparagine and other amino acids, flavonoids (caffeic acid, kaempferol, and isoquercetin), coumarin, tannins, starch, and other important active compounds (Gudej, 1991; AlSnafi, 2013). Beside callus-mediated synthesis of active compounds, this loosely arranged parenchymatous tissue is used as a primary source for somatic embryo production. Recently, Naz and coworkers (2017) reported a direct somatic embryo formation in Althea from an intermodal explant on a medium amended with 2, 4-D and BAP. This embryogenic tissue is also similarly exploited for obtaining protoplasts and in studies of genetic manipulation (Prange et al., 2010). In the present study, the in vitro induction of callus and shoot regeneration protocols were established by assessing and optimizing the response of explants under in vitro conditions. The effect and comparison of various PGRs on callus induction, shoot regeneration, and root induction were performed. Finally, in vitro-regenerated plants were transferred to outdoor conditions.

\section{Materials and methods}

\section{Plant material and surface sterilization}

The seeds of Althaea (Althaea officinalis L.) were procured from an herb garden and were used as the experimental material. Healthy seeds were collected and washed with cetrimide for 4-6 min, and washed under flowing tap water for $20 \mathrm{~min}$. The seeds were then immersed in $70 \%$ ethanol for approximately $4-5 \mathrm{~min}$ and later washed with distilled water. The seeds were finally surface sterilized with $\mathrm{HgCl}_{2}(0.05 \% \mathrm{v} / \mathrm{v})$ for $4 \mathrm{~min}$, and washed repeatedly with autoclaved distilled water to eliminate the traces of $\mathrm{HgCl}_{2}$. The seeds were placed on MS germination medium that contained macro- and micro salts and vitamins (Murashige and Skoog, 1962), but without plant growth regulators (PGRs). Young leaves, stem nodes (nodal stem), and roots of germinated seedlings (6-8 days old) were used as explants. Different 2, 4-dichlorophenoxyacetic acid (2,4-D), 6-benzylaminopurine (BA), and 1-naphthaleneacetic acid (NAA) concentrations were added at different stages of morphogenesis. The $\mathrm{pH}$ of the media was maintained at 5.7 before sterilization at $121^{\circ} \mathrm{C}$. All the cultures were incubated in a growth room, maintaining a temperature of $25^{\circ} \mathrm{C}$ $\pm 2^{\circ} \mathrm{C}$ in a 16 -h photoperiod created by a cool white (Phillips, India) tube light with an intensity of $40 \mathrm{Wm}^{-2} \mathrm{~S}^{-1}$.

\section{Callus induction}

The leaves, stem nodes, and roots were individually cultured on an MS medium supplemented with 3\% sucrose and $100 \mathrm{mg} / 1$ of inositol. The media were additionally amended with various $2,4-\mathrm{D}$ concentrations $(0.25$, 0.5 , and $1.0 \mathrm{mg} / \mathrm{l}$ ) to induce calli. The $2,4-\mathrm{D}$ concentrations were maintained at the same level during callus maintenance. The cultures were sub-cultured regularly at 4-week intervals. Only effective doses of PGRs were continued. Callus started to appear within 5-7 days; the induction frequency, nature, and other morphology of callus were observed.

\section{Growth of callus biomass}

Approximately $300 \mathrm{mg}$ of calli were cultivated on MS media amended with the following concentrations of 2,4-D: $0.25,0.5$, and $1.0 \mathrm{mg} / \mathrm{l}$. The callus biomass yield was monitored at regular 2-week intervals, i.e., after 2, 4 , and 6 weeks. The callus biomass was measured in grams and was plotted.

\section{Induction of shoots}

The stem nodes of in vitro germinated seedlings were cultured on a shoot regeneration medium, supplemented with different BAP concentrations $(0.5,1.0$, and 
Table 1. Callus induction frequency (\%) from various explants in Althaea officinalis. The MS medium was amended with different concentrations of 2,4-D, and data were scored after 6 weeks of culture

\begin{tabular}{c|c|c|c}
\hline $\begin{array}{c}2,4-\mathrm{D} \\
{[\mathrm{mg} / \mathrm{l}]}\end{array}$ & Root & Leaf & Stem node \\
\hline 0.25 & $14.5 \pm 2.33^{\mathrm{c}}$ & $21.1 \pm 3.12^{\mathrm{b}}$ & $42.1 \pm 4.22^{\mathrm{a}}$ \\
\hline 0.50 & $17.5 \pm 2.28^{\mathrm{c}}$ & $27.9 \pm 3.65^{\mathrm{b}}$ & $42.5 \pm 4.44^{\mathrm{a}}$ \\
\hline 1.0 & $27.5 \pm 3.33^{\mathrm{c}}$ & $39.1 \pm 3.34^{\mathrm{b}}$ & $62.1 \pm 5.16^{\mathrm{a}}$ \\
\hline
\end{tabular}

Values are means \pm standard errors of three replicates of two experiments; within each row, means followed by the same letter are not significantly different at $P \leq 0.05$ according to DMRT
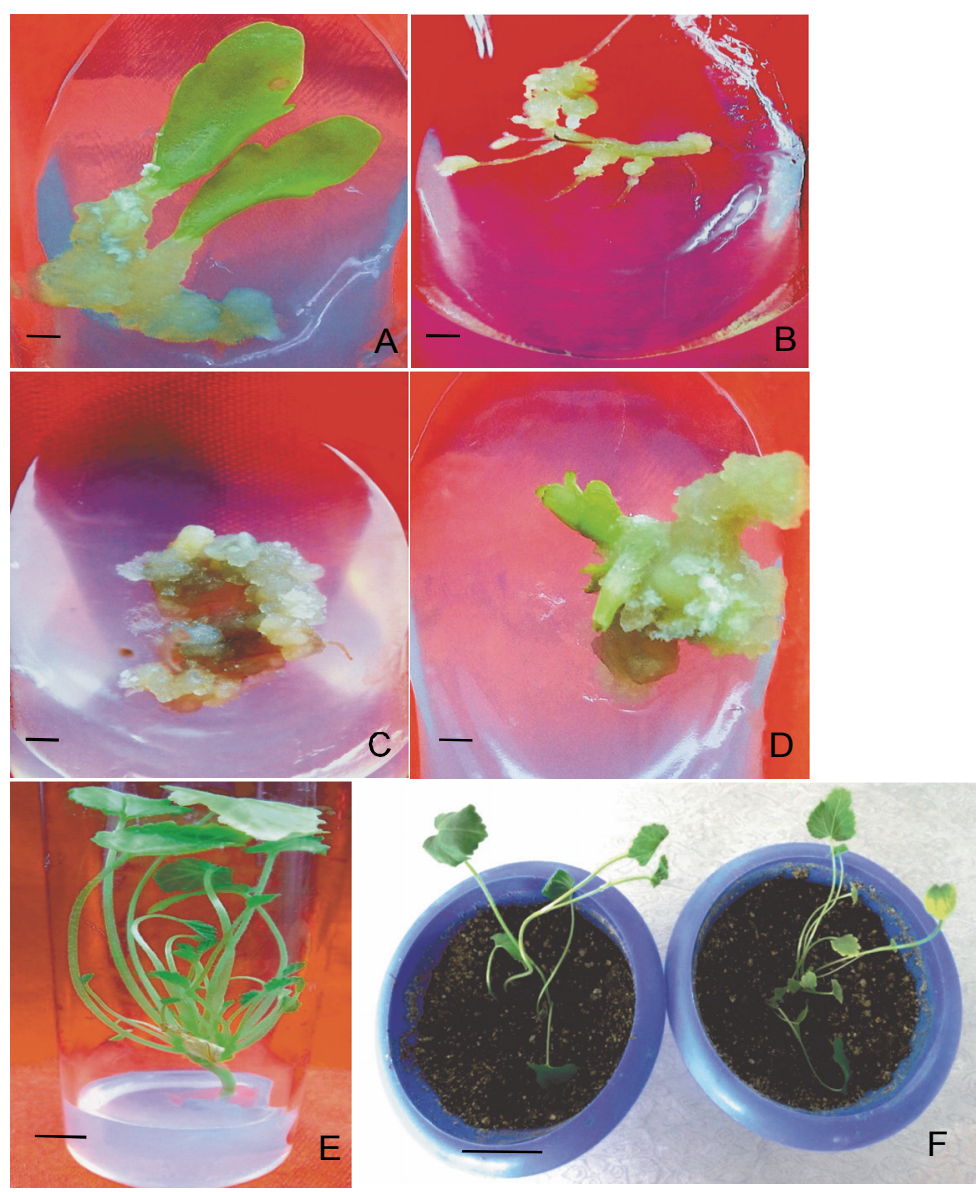

Fig. 1. Callus induction and plant regeneration in Althaea; A, B, and C - calli induced from leaf, root, and nodal explants; D - shoot initiation from nodal callus ( $\mathrm{bar}=0.5 \mathrm{~cm}$ ); $\mathrm{E}$ - multiple shoot bud formation in BAP-amended medium; $\mathrm{F}$ - regenerated plants in plastic pots under outdoor conditions (bars $\mathrm{A}-\mathrm{E}=0.5 \mathrm{~cm} ; \mathrm{F}=5 \mathrm{~cm}$ )

$2.0 \mathrm{mg} / \mathrm{l})$. The number of shoot buds was counted after 4 weeks of culture. The organogenetic behavior of callus was investigated by culturing calli onto a variety of PGRamended media primarily supplemented with BAP alone $(0.5,1.0$, and $2.0 \mathrm{mg} / \mathrm{l})$ or together with NAA $(0.25$ and $0.5 \mathrm{mg} / \mathrm{l})$.

\section{Root induction}

In vitro regenerated healthy shoots $(1.5-2.0 \mathrm{~cm})$ were excised at the base and were cultured for root induction on an MS solid medium, supplemented individually with NAA (1-naphthaleneacetic acid), IAA 


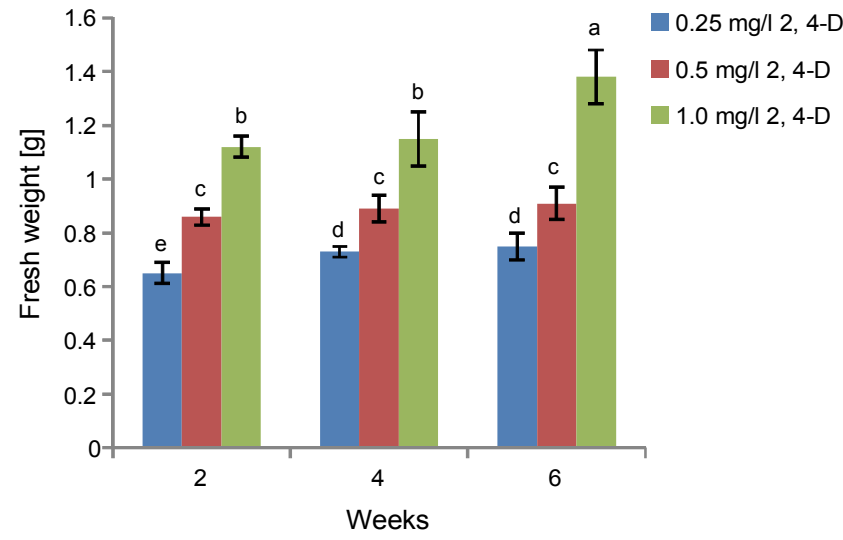

Fig. 2. Callus biomass (g, fresh weight) growth of Althaea. MS medium was supplemented with different concentrations of 2, 4-D. Mean values in the bars followed by different letters are significantly different (at $P=0.05$ ) according Duncan's Multiple Range Test

(indole-3-acetic acid), and IBA (indole-3-butyric acid) at 2 different concentrations $(0.5$ and $1.0 \mathrm{mg} / \mathrm{l})$. The number of roots was counted, and the root length was measured.

\section{Transplantation of plants}

The rooted shoots were washed thoroughly to remove any remaining agar and were transferred to plastic pots containing soilrite and sand (1:1). The plastic pots were covered with polythene bags with pored polythene for maintaining humidity and were kept for 10-15 days in the same incubation room at $25^{\circ} \mathrm{C} \pm 2{ }^{\circ} \mathrm{C}$ for a 16 - $\mathrm{h}$ photoperiod. The polythene covers were gradually removed, and the regenerated plants were transferred to outdoor conditions.

\section{Statistical analysis}

The experiments involving the effects of PGRs on the callusing of different explants were conducted according to randomized design. The callus induction percentage was observed after 6 weeks of culture. The collected data were subjected to a statistical analysis to assess the reproducibility of experiments. The data on the effects of PGRs at various stages of morphogenesis were analyzed, and the values are means of three replicates of two experiments. The mean values were presented using Duncan's multiple range test (DMRT) at $P \leq 0.05$.

\section{Results and discussion}

In this study, the influence of various concentrations of 2,4-D on callogenesis was investigated (Table 1).
Three different explant types (leaves, roots, and stem nodes) were tested for their ability to grow calli. Within about a week, calli started to appear at the attached parts of all types of explants. The leaf callus (Fig. 1A) was yellowish-white in color, friable, and fast growing. Callus was also induced from roots (Fig. 1B) and stem nodes (Fig. 1C). Small-to-prolific callus growth was noted on the root surfaces, but the callus growth was relatively poor in nodal explants. Table 1 shows that callus induction was more prolific in $1.0 \mathrm{mg} / \mathrm{l}$ of 2,4-D in which $27.5 \%$ and $39.1 \%$ callus induction frequencies were noted from the root and leaf explants, respectively. In the MS medium supplemented with $1.0 \mathrm{mg} / \mathrm{l}$ of 2,4-D, the callus induction frequency was the highest $(62.1 \%)$ in the stem nodes. The moderate dose of $2,4-\mathrm{D}(0.5 \mathrm{mg} / \mathrm{l})$ was also efficient in inducing callus.

Juvenile leaves having a length of approximately 0.5 $1.0 \mathrm{~cm}$ were noted to be very effective explants in producing calli, followed by roots and nodes. The biggest leaves did not show any callus regeneration ability. The present study also demonstrated that calli were primarily induced from the base as compared to the other parts of the leaves. The orientation and placement of leaves on the nutrient media had a strong influence on the callus development. The leaves placed shiny side (ventral) above (away from the medium) had better callus growth than those on the dorsal sides (data not shown). Although little is known about this differential behavior, different physiological gradients and endogenous PGR levels are known to cause varied responses of explants (Bandyopadhyay et al., 1999; Ling et al., 2013). The age of explants, differential nutritional gradients, and cultivar-dependent responses of explants were earlier noted to be responsible for the varied responses in other investigated plant materials (Mujib 2005; Ghosh et al., 2014).

Figure 2 shows that the addition of 2,4-D to an MS medium resulted in good callus growth and in $0.5-\mathrm{mg} / \mathrm{l}$ 2,4-D-supplemented medium, the callus biomass growth was considerably high ( $1.15 \mathrm{~g}$ after 6 weeks of incubation). The callus biomass growth was even better in the $1.0 \mathrm{mg} / 1-2,4-\mathrm{D}$-added medium as $0.75 \mathrm{~g}$ of callus grew to $1.38 \mathrm{~g}$ after 6 weeks of culture. The external supplementation with 2,4-D was often performed in in vitro cultures to induce and promote callus growth as this PGR is regarded to be an important signaling compound in triggering cell division and post-divisional growth pro- 
Table 2. Shoot regeneration ability of calli obtained from various explants on MS medium amended with different PGRs

\begin{tabular}{c|c|c|c|c}
\hline \multicolumn{2}{c|}{ PGRs } & \multicolumn{3}{c}{ Callus \% showing shoot regeneration } \\
\hline BAP & NAA & Stem & Root & Leaf \\
\hline 0.0 & 0.0 & $0.0 \pm 0.0^{\mathrm{c}}$ & $0.0 \pm 0.0^{\mathrm{c}}$ & $0.0 \pm 0.0^{\mathrm{c}}$ \\
0.5 & 0.0 & $0.0 \pm 0.0^{\mathrm{c}}$ & $0.0 \pm 0.0^{\mathrm{c}}$ & $0.0 \pm 0.0^{\mathrm{c}}$ \\
1.0 & 0.0 & $0.0 \pm 0.0^{\mathrm{c}}$ & $0.0 \pm 0.0^{\mathrm{c}}$ & $0.0 \pm 0.0^{\mathrm{c}}$ \\
2.0 & 0.0 & $0.0 \pm 0.0^{\mathrm{c}}$ & $0.0 \pm 0.0^{\mathrm{c}}$ & $0.0 \pm 0.0^{\mathrm{c}}$ \\
1.0 & 0.25 & $0.0 \pm 0.0^{\mathrm{c}}$ & $0.0 \pm 0.0^{\mathrm{c}}$ & $0.0 \pm 0.0^{\mathrm{c}}$ \\
1.0 & 0.5 & $10.0 \pm 0.32^{\mathrm{a}}$ & $0.0 \pm 0.0^{\mathrm{c}}$ & $0.0 \pm 0.0^{\mathrm{c}}$ \\
2.0 & 0.25 & $4.19 \pm 0.6^{\mathrm{b}}$ & $0.0 \pm 0.0^{\mathrm{c}}$ & $0.0 \pm 0.0^{\mathrm{c}}$ \\
2.0 & 0.5 & $0.0 \pm 0.0^{\mathrm{c}}$ & $0.0 \pm 0.0^{\mathrm{c}}$ & $0.0 \pm 0.0^{\mathrm{c}}$ \\
\hline
\end{tabular}

Values are means \pm standard errors of 3 replicates of two experiments; within each column, means followed by the same letter are not significantly different at $P \leq 0.05$ according to DMRT

Table 3. Shoot numbers grown on the BAP-supplemented MS medium

\begin{tabular}{c|c|c|c|c}
\hline $\begin{array}{c}\text { PGR } \\
{[\mathrm{mg} / \mathrm{l}]}\end{array}$ & 4 weeks & 8 weeks & 4 weeks & 8 weeks \\
\hline BAP & \multicolumn{2}{|c|}{ no. of shoots } & \multicolumn{2}{|c}{ no. of leaves } \\
\hline 0.0 & $0.0 \pm 0.00^{\mathrm{d}}$ & $1.15 \pm 0.32^{\mathrm{d}}$ & $0.0 \pm 0.00^{\mathrm{d}}$ & $2.22 \pm 0.38^{\mathrm{d}}$ \\
\hline 0.5 & $4.5 \pm 0.53^{\mathrm{c}}$ & $6.5 \pm 1.26^{\mathrm{c}}$ & $5.12 \pm 1.64^{\mathrm{c}}$ & $6.37 \pm 2.32^{\mathrm{c}}$ \\
\hline 1.0 & $7.8 \pm 1.2^{\mathrm{b}}$ & $13.2 \pm 2.82^{\mathrm{a}}$ & $6.2 \pm 1.50^{\mathrm{b}}$ & $12.42 \pm 2.87^{\mathrm{b}}$ \\
\hline 2.0 & $8.8 \pm 1.8^{\mathrm{a}}$ & $10.6 \pm 2.24^{\mathrm{b}}$ & $12.87 \pm 2.82^{\mathrm{a}}$ & $14.76 \pm 3.22^{\mathrm{a}}$ \\
\hline
\end{tabular}

Values are means \pm standard errors of three replicates of two experiments; within each column, means followed by the same letter are not significantly different at $P \leq 0.05$ according to DMRT

Table 4. Root induction of Althaea officinalis in a medium supplemented with two different concentrations of NAA, IBA, and IAA (data scored after 4 weeks)

\begin{tabular}{c|c|c}
\hline $\begin{array}{c}\text { PGR } \\
{[\mathrm{mg} / \mathrm{l}]}\end{array}$ & $\begin{array}{c}\text { Mean number } \\
\text { of roots/shoot }^{2}\end{array}$ & $\begin{array}{c}\text { Root length } \\
{[\mathrm{cm}]}\end{array}$ \\
\hline 0.0 & $1.36 \pm 0.70^{\mathrm{e}}$ & $0.42 \pm 0.12^{\mathrm{f}}$ \\
\hline \multicolumn{3}{|c}{$\mathrm{NAA}$} \\
\hline 0.50 & $5.60 \pm 2.70^{\mathrm{d}}$ & $2.79 \pm 1.5^{\mathrm{b}}$ \\
\hline 1.0 & $7.57 \pm 2.69^{\mathrm{b}}$ & $3.19 \pm 1.1^{\mathrm{a}}$ \\
\hline \multicolumn{3}{|c}{$\mathrm{IBA}$} \\
\hline 0.50 & $8.8 \pm 1.81^{\mathrm{a}}$ & $1.91 \pm 0.65^{\mathrm{e}}$ \\
\hline 1.0 & $6.83 \pm 2.56^{\mathrm{c}}$ & $2.18 \pm 0.70^{\mathrm{d}}$ \\
\hline \multicolumn{3}{|c}{ IAA $^{\mathrm{I}}$} \\
\hline 0.50 & $5.65 \pm 1.81^{\mathrm{d}}$ & $2.35 \pm 0.82^{\mathrm{c}}$ \\
\hline 1.0 & $6.66 \pm 1.18^{\mathrm{c}}$ & $2.66 \pm 0.68^{\mathrm{b}}$ \\
\hline
\end{tabular}

Values are means \pm standard errors of three replicates of two experiments; within each column, means followed by the same letter are not significantly different at $P \leq 0.05$ according to DMRT 
cesses (Pasternak et al., 2002; Feher, 2015). The root calli were friable, while the nodal and leaf calli were somewhat hard and compact. The calli of different sources were cultured on various PGR-amended media (Table 2); except for a very poor shoot regeneration ability of a stem node callus (Fig. 1D), no shoot bud regeneration was noted from the root and leaf calli even after prolonged in vitro cultures.

Further, in vitro germinated seedlings were used as explants for multiple shoot formation. Table 3 shows that multiple shoot bud formation was more pronounced in a $1.0 \mathrm{mg} / \mathrm{l}$ BAPsupplemented MS medium in which the highest number of shoot buds (7.8) was formed. The number of shoots increased with time, and at the end of the eighth week, 13.2 shoot buds were produced. The multiple shoot bud formation was also significantly high in the $2.0 \mathrm{mg} / \mathrm{l}-\mathrm{BAP}$-amended medium in which 10.6 shoots were induced after 8 weeks of culture. In the $0.5 \mathrm{mg} / \mathrm{l}$ BAP-added medium, the number of shoots formed was relatively low (only 6.5). The first signs of shoot bud formation were noted after approximately 1 week of incubation as small outgrowths, which turned into buds; these induced shoot buds grew moderately in the same BAP-amended medium and produced a good number of leaves. It has been shown that in Althaea, multiple shoots were formed from nodal explants on an MS medium, and BAP was noted to be very efficient in promoting shoot buds (Fig. 1E). Moderate BAP levels (1.0 and $2.0 \mathrm{mg} / \mathrm{l}$ ) were identified to be effective treatments, very similar to the findings of other researchers, who reported that shoots were frequently formed on BAPamended MS media (Mok and Mok, 2001; Srivastava and Joshi, 2009; Ashraf et al. 2014). Besides BAP, shoot bud development, shoot growth, and other related morphogenetic responses have been noted in an MS medium supplemented with various cytokinin concentrations in different investigated plant materials (Ashraf, 2014).

The induced shoot buds were excised and approximately 1.5-2.0 cm of shoots was placed on an MS medium supplemented with various auxins to induce and promote root growth. Three auxins (IBA, NAA, and IAA) were tested at two different concentrations, and the roots were induced in all treatments at varying numbers (Table 4). IBA was noted to be very efficient in inducing roots, followed by NAA and IAA. IBA at $0.5 \mathrm{mg} / 1$ produced the highest number of roots ( 8.8 roots/shoot), followed by a treatment with NAA at $1.0 \mathrm{mg} / \mathrm{l}$, which induced 7.57 roots/shoot. Although IBA induced a higher number of roots, they grew better in an NAA-added medium. Both 1.0 and $0.5 \mathrm{mg} / \mathrm{l}$ of NAA stimulated root growth under the culture conditions. IAA was also observed to be efficient in promoting root growth, maximum $(2.66 \mathrm{~cm})$ being at $1.0 \mathrm{mg} / \mathrm{l}$ of IAA. The effect of various auxins on inducing the formation of roots and the root growth is summarized in Table 4. It is clear that all the root-promoting auxins played an important role in inducing in vitro rooting in Althaea. The stimulatory role of auxins in promoting roots has been reported in a number of studies (Naz and Anis, 2012; Aslam, 2013), and IBA, in particular, has been widely exploited to induce roots in tissue culture-regenerated plants (Dipti et al., 2014). Recently, Kher and coworkers (2016) reported that half the MS medium supplemented with $8.05-\mu \mathrm{M} \alpha$-naphthaleneacetic acid induced the formation of prolific roots in Clerodendrum phlomidis. The in vitro rooted Althaea shoots were later transferred to outdoor conditions where they adapted well and grew normally (Fig. 1F). Thus, a successful regeneration protocol was established in Althaea in which further investigations of (the) enriched levels of phytocompounds can be initiated. Fast induction of callus from diverse sources can also be used for developing transgenic Althaea cell lines with improved traits.

\section{Summary}

Callus induction, callus biomass growth, and plant regeneration protocol were established in $A$. officinalis in which the roles of PGRs in in vitro morphogenesis were investigated. Prolific calli were formed from leaves and roots in 1.0-mg/1 2,4-D-supplemented medium, but the induced calli were non-organogenic/embryogenic in nature. Multiple shoots were formed in the $1.0 \mathrm{mg} / \mathrm{l}$ BAP-supplemented medium. The shoots were rooted in an IBA $(0.5 \mathrm{mg} / \mathrm{l})$-added medium before being transferred to outdoor conditions.

\section{Authors' contribution statement}

The first author conceived the idea, wrote, and edited the manuscript; the second author performed most of the experiments, and the other authors helped in designing the experiment layout and creating tables, figures, and photographs.

\section{Acknowledgements}

The authors are grateful to the Central Instrumentation Facility (CIF) and the Department of Botany, Jamia Hamdard 
(Hamdard University), for providing the necessary research facilities.

\section{Conflicts of interest}

The authors declare that there is no conflict of interest.

\section{References}

Ali Esmail Al-Snafi (2013) The pharmaceutical importance of Althaea officinalis and Althaea rosea: a review. Int. J. PharmTech Res. 5(3): 1378-1385.

Anonymous (2003) The wealth of India. A dictionary of Indian raw materials and industrial products. Council of Scientific and Industrial Research, New Delhi, India, pp 207-208.

Ashraf M.F., Aziz M.A., Kemat N., Ismail I. (2014) Effect of cytokinin types, concentrations and their interactions on in vitro shoot regeneration of Chlorophytum borivilianum Sant. \& Fernandez. Electro. J. Biotechnol. 17(6): 275279.

Aslam J., Mujib A., Sharma M.P. (2013) In vitro micropropagation of Dracaena sanderiana Sander ex Mast: an important indoor ornamental plant. Saudi J. Biol. Sci. 20: 63-68.

Bandyopadhyay S., Cane K., Rasmussen G., Hamill J.D. (1999) Efficient plant regeneration from seedling explants of two commercially important temperate eucalypt species - Eucalyptus nitens and E. globulus. Plant Sci. 140: 189-198.

Blumenthal M., Goldberg A., Brinckmann J. (2000) Herbal medicine: expanded commission E monographs. Austin American Botanical Council, pp. 244-248.

Dipti T., Fatima S., Mujib A. (2014) Morphological anomalies in somatic embryo structure in Catharanthus roseus: improving embryo germination by amending plant growth regulators, activated charcoal and sucrose level. British Biotechnol. J. 4(1): 10-20.

Dube P., Gangopadhyay M., Dewanjee S., Ali M.N. (2011) Establishment of a rapid multiplication protocol of Coleus forskohlii Briq. and in vitro conservation by reduced growth. Ind. J. Biotechnol. 10: 228-231.

Elmastas M., Ozturk L., Gokce I., Erenler R., Aboul-Enein H.Y. (2004) Determination of antioxidant activity of marshmallow flower (Althaea officinalis). Anal. Lett. 37: 1859-1869.

Feher A. (2015) Somatic embryogenesis - stress-induced remodeling of plant cell fate. Biochim. Biophys. Acta 1849(4): 385-402.

Ghosh S., Sengupta S., Pal A. (2014) Abscisic acid, one of the key determinants of in vitro shoot differentiation from cotyledons of Vigna radiata. Amer. J. Plant Sci. 5: 704-713.

Hage-Sleiman R., Mroueh M., Daher C.R. (2011) Pharmacological evaluation of aqueous extract of Althaea officinalis flower grown in Lebanon. Pharm. Biol. 49: 327-333.

Gudej J. (1991) Flavonoids, phenolic acids and coumarins from the roots of Althaea officinalis. Planta Med. 57: 284-285.
Kher M.M., Soner D., Srivastava N., Nataraj M., TeiXiera da Silva J.A. (2016) Micropropagation of Clerodendrum phlomidis L.F. J. Hort. Res. 24(1): 21-28.

Ling A.P.K., Tan K.P., Hussein S. (2013) Comparative effects of plant growth regulators on leaf and stem explants of Labisia pumila var. alata. J. Zhejiang Univ. Sci. B. 14(7): 621-631.

Mok D.W.S., Mok M.C. (2001) Cytokinin metabolism and action. Annu. Rev. Plant Physiol. Plant Mol. Biol. 52: 89-118.

Munir M., Hussain A., Haq I., Qureshi R., Munazir M., Arshad M., Leghari M.K. (2012) Callogenesis potential of cotyledonary explants of Althaea rosea L. from Pakistan. Pak. J. Bot. 44: 271-275.

Mujib A. (2005) In vitro regeneration of Sandal (Santalum album L.) from leaves. Turk. J. Bot. 29: 63-67.

Murashige T., Skoog F. (1962) A revised medium for rapid growth and bioassays with tobacco tissue cultures. Physiol. Plant. 15: 473-497.

Naz R., Anis M. (2012) Acceleration of adventitious shoots by interaction between exogenous hormone and adenine sulphate in Althaea officinalis L. Appl. Biochem. Biotechnol. 168: 1239-1255.

$\mathrm{Naz}$ R., Anis M., Alatar A.A. (2017) Embling production in Althaea officinalis L., through somatic embryogenesis and their appraisal via histological and scanning electron microscopical studies. Appl. Biochem. Biotechnol. DOI 10.1007/s12010-016-2391-2.

Pasternak T.P., Prinsen E., Ayaydin F., Miskolezi P., Potters G., Asard H., Van Onckelen A., Dudits D., Feher A. (2002) The role of auxin, $p H$, and stress in the activation of embryogenic cell division in leaf protoplast derived cells of alfalfa. Plant Physiol. 129: 1807-1819.

Petkewich R. (2006) What's that stuff? Marshmallow. Chem. Engineer News 84(16): 41.

Prange A.N.S., Serek M., Bartsch M., Winkelmann T. (2010) Efficient and stable regeneration from protoplasts of Cyclamen coum Miller via somatic embryogenesis. Plant Cell Tiss. Org. Cult. 101(2): 171-182.

Sadighara P., Gharibi S., Jafari A.M., Khaniki G.J., Salari S. (2012) The antioxidant and flavonoids contents of Althaea officinalis $L$. flowers based on their color. Avicenna J. Phytomed. 2(3): 113-117.

Srivastava A., Joshi A.G. (2009) In vitro behavior of nodal explants of Portulaca grandiflora under the influence of cytokinins. Acta. Univ. Latv. 753: 43-48.

Uyoh E.A., Nkang A.E., Eneobong E.E. (2003) Biotechnology, genetic conservation and sustainable use of bioresources. Afr. J. Biotechnol 2: 704-709. 